\title{
Relationship between Sense of Coherence and oral health in adults and elderly Brazilians
}

\section{Rosane Silvia DAVOGLIO(a) Claídes ABEGG(b) \\ Victor Nascimento FONTANIVE ${ }^{(c)}$ \\ Mônica Maria Celestina de OLIVEIRA $^{(\mathrm{d})}$ \\ Denise Rangel Ganzo de Castro AERTS(e) \\ Charles Henrique CAVALHEIRO(f)}

(a) Universidade Federal do Pampa - UNIPAMPA, School of Medicine, Uruguaiana, RS, Brazil.

(b) Universidade Federal do Rio Grande do Sul - UFRGS, School of Dentistry, Department of Preventive and Social, Porto Alegre, RS, Brazil.

(c) Grupo Hospitalar Conceição, Community Health Service, Porto Alegre, RS, Brazil.

(d)Fundação Universidade Federal de Ciências da Saúde de Porto Alegre - UFCSPA, Department of Public Health, Porto Alegre, RS, Brazil.

(e) Universidade Luterana do Brasil, Postgraduate Program in Public Health, Canoas, RS, Brazil.

(f) Universidade Federal de Santa Maria - UFSM, Center of Health Sciences, Postgraduate Program in Dental Sciences, Santa Maria, RS, Brazil.

Declaration of Interests: The authors certify that they have no commercial or associative interest that represents a conflict of interest in connection with the manuscript.

Corresponding Author:

Rosane Silvia Davoglio

E-mail: rosanedavoglio@gmail.com

DOI: 10.1590/1807-3107BOR-2016.vol30.0056

Submitted: Sep 07, 2015

Accepted for publication: Jan 31, 2016

Last revision: Mar 06, 2016
Abstract: The purpose of this study was to investigate the relationship between Sense of Coherence (SOC) and oral health clinical variables (number of teeth present and absence of need for dental prostheses). The sample consisted of 720 adults and elderly Brazilians. The data were collected at home using the SOC-13 scale - a form of clinical examination for the evaluation of oral conditions - and a questionnaire evaluating socioeconomic aspects and the use of dental services. Statistical analysis, both univariate and multivariate, was performed by Poisson regression with robust variance adjustment. The average age of the participants was 60.2 years, and they were predominantly female (57.8\%). Among the participants who had a strong SOC, the absence of the need for dental prostheses was 34\% higher than among those with a weak SOC, demonstrating a significant difference between the groups $(\mathrm{PR}=1.34,95 \% \mathrm{CI}=1.06-1.70 ; \mathrm{p}=0.015)$. Individuals who had a strong SOC had a $5 \%$ higher prevalence of 14 or more existing teeth than those with a weak SOC, which was statistically significant after adjustment for co-factors $(\mathrm{PR}=1.05,95 \% \mathrm{CI}=1.01-1.11, \mathrm{p}=0.033)$. A strong personal Sense of Coherence has a beneficial influence on the oral health of adults and older people in Brazil.

Keywords: Sense of Coherence; Oral Health; Health Behavior; Health Promotion; Dental Prosthesis.

\section{Introduction}

Sense of Coherence (SOC) is a resource for coping with stressors; it is related to quality of life, and can be considered a predictor of health., The salutogenic theory proposed by Antonovsky ${ }^{3}$ - of which SOC is the core construct - argues that understanding the origin of health is more important than identifying the causes of disease. According to Antonovsky, ${ }^{3}$ SOC is "a global orientation that expresses the extent to which one has a pervasive, enduring though dynamic feeling of confidence that (1) the stimuli from one's internal and external environments in the course of living are structured, predictable, and explicable; (2) the resources are available to one to meet the demands posed by these stimuli; and (3) these demands are challenges, worthy of investment and engagement". ${ }^{3}$

The SOC has been shown to be a promising resource for establishing healthy behaviors $4,5,6,7,8,9,10,11,12,13,14,15,16$ and a positive self-perception of oral health, ${ }^{14,16}$ which increases the interest in investigating its relationship 
with clinical oral health. Coping strategies may have a protective effect against negative oral health outcomes, operating through behavioral pathways. ${ }^{17}$ The SOC is considered a determinant psychosocial factor of behaviors related to oral health in adolescents, 5 which may be reflected in improved oral health in adulthood. ${ }^{12}$ However, the relationship of SOC with physical health is more difficult to demonstrate. ${ }^{18}$ Since there is consistent evidence on the relationship between SOC and oral health behavior, the effect of the SOC on clinical oral health conditions may be mediated by these behaviors.

The literature shows that SOC can change throughout life. ${ }^{19}$ Thus, understanding the behavior of SOC in the older age groups, in an effort to look for ways to stimulate it, becomes a relevant strategy to improve the quality of life of adults and the elderly. Recently, Bernabé et al. ${ }^{20}$ conducted one of the first studies that investigated the relationship of the SOC with clinical oral conditions, and found a strong association between the SOC and better oral conditions, indicating the relevance of directing inquiries accordingly.

In Brazil, this is the first study to investigate this relationship in adults and the elderly. For developing countries, the World Health Organization (WHO) defined elderly people as those aged above 60 years. The age group 50-59 years was included in the study because of its increase in the Brazilian population. ${ }^{1,21,22}$ There is a lack of studies investigating the oral health of older adults (50-59). Considering the aging process currently faced by the Brazilian population, the inclusion of this group is paramount to developing policies favoring its oral health and well-being.

The aim of this study was to investigate the relationship between the SOC and clinical oral health in adults and elderly Brazilians aged 50 to 74 years, testing the hypothesis that a strong SOC is associated with better clinical conditions of oral health (number of teeth present and need for dental prostheses).

\section{Methodology}

A cross-sectional population-based study was conducted in Porto Alegre, the main city of the state of Rio Grande do Sul, Brazil.

\section{Sample}

The sample size was calculated considering an outcome prevalence of 0.50 , a confidence interval of $95 \%$ and bilateral error margin of $4 \%$. Taking into account a design effect equal to 1.5 and possible non-answers and losses (10\%), the sample consisted of 793 participants. Data analysis was conducted on 720 individuals.

The subjects of the study were selected through multistage, proportional, random sampling. ${ }^{23}$ Porto Alegre is composed of 16 geographic areas called health districts. Health districts have similar social and epidemiological characteristics. A health district is formed by taking into account social and epidemiological characteristics. The following selections were all made randomly: first, three health districts, then, the census sectors from each district, the city block for data collection, and, finally, the corner from which the visits would start.

The number of subjects interviewed in the health districts was proportional to the total number of people living in each district. Home visits were conducted, and only one individual from each household was interviewed. If there was more than one eligible individual, a randomized selection was performed. Individuals not living in the area, whose age range was different from 50 to 74 years, and having apparent dementias or mental disorder were excluded.

\section{Instruments and measures}

The data was collected in people's homes by four pairs of previously trained and calibrated examiners and recorders, through interviews and clinical examinations. Theinstruments consisted of:(I) a structured questionnaire on socioeconomic, demographic data, use of dental services adapted from the SB Brazil 2003, ${ }^{24}$ the National Oral Health Survey conducted in the year 2003, including the age groups adopted by WHO; (II) the reduced version of the SOC or SOC-13 scale, ${ }^{25}$ (III) clinical examination performed under artificial light, using flat mirrors and CPI probes, according to $\mathrm{WHO}$ criteria complemented by SB Brazil 2003. ${ }^{24}$

The SOC scale is a standard scale developed by Antonovsky ${ }^{3}$ and originally written in Hebrew and in English to be used cross-culturally. The original version of the scale has 29 items, whereas the short version has 13, and is known as the SOC-13 
version. The SOC Scale has been translated and used in more than thirty languages in countries around the world, and has been applied in all social classes among adolescents and adults of all ages. ${ }^{1}$ The short version has been validated and trans-culturally adapted for use among mothers of Brazilian children between 1 and 5 years, ${ }^{26}$ but has not yet been used in the Brazilian population, with characteristics similar to those of the present study.

The SOC-13 comprises 13 questions and three domains, with answers presented in a 7-point Likert scale. Questions 2, 6, 8, 9 and 11 of the instrument refer to understanding (domain comprehensibility); questions $3,5,10$ and 13 , to management (domain manageability), and questions 1, 4, 7 and 12, to meaning (domain meaningfulness); however, it was recommended ${ }^{3}$ that the total SOC score should be used in the analysis, and was thus adopted in this study.

The SOC score is calculated by adding up the points for all items, and can range from 13 to 91 . The SOC is stronger, the higher the score. After calculating their score, participants with missing values on more than three items were treated as "missing". When there were three or fewer missing values, these were replaced by the mean value of the SOC items, as described by Suominen et al. ${ }^{27}$

Four of the thirteen questions were negatively formulated by inverse scoring, i.e., the scores were reversed in the analysis so that a high score represented a strong SOC. The instrument also contained two questions regarding face-to-face validation, based on Streiner and Norman. ${ }^{28}$ in order to adapt the instrument cross-culturally for use in this population. The validation result showed that most found it easy to understand the questions $(86.9 \%)$ and the responses (85.4\%), and no significant differences were found in relation to age (p 0.165 and 0.682 , respectively), according to the chi-square test.

A pilot study was conducted on a convenience sample of 40 participants with characteristics similar to those of the participants eligible for the study, to test the questionnaire application and to train the examiners. During this study, the reliability/reproducibility of the structured interviews and the clinical examinations were validated, with replication in $5 \%$ of the sample, and were reassessed one week after the first evaluation. The level of intra- and interexaminer agreement on all the oral indices was evaluated by Kappa, yielding $>0.81$ and 0.76 , respectively, at the beginning of the research. During the study, these coefficients were $>0.98$ and 0.88 for intraand interexaminer reproducibility, respectively, showing almost perfect agreement.

The SOC reliability was tested by internal consistency and stability of the measure (test-retest). The internal consistency of the overall score, calculated by Cronbach's Alpha, was 0.80, indicating good consistency, similar to that observed by Naaldenberg et al. ${ }^{29}$ The intraclass correlation coefficient (ICC) was used to perform the test-retest, and had a result of 0.79 . The split-half reliability of the aforementioned Dutch study ranged from 0.68 to 0.86 .

The SOC score was dichotomized into "weak" for values lower than the median and "strong" for values equal to or greater than the median. The median was used in other studies ${ }^{9}$ as a cut-off point, when the purpose was to categorize the scores of SOC into two categories, weak or strong. In sociodemographic variables, age was collected in years and further categorized as adults (50-59 years) and elderly people (60-74 years).

Family income was collected as a continuous variable, and took into account the gross family income in reais (Brazilian currency), categorized based on the prevailing Brazilian minimum monthly wage of four hundred and fifteen $(\mathrm{R} \$ 415.00)$ reais ( $\leq 2$ minimum wages; between 2 and 5 minimum wages; > 5 minimum wages). The definition of schooling considered the number of years of schooling completed in formal education, not counting the repeated grades/years, and also the specialty courses/graduate education, dichotomized by the frequency distribution ( $<6$ years; $\geq 6$ years). ${ }^{23}$

Oral health variables were: (I) behavioral variables that included dental attendance within the previous year (no; yes), and the reason for dental attendance (curative; preventive), both informed by the participant; (II) clinical variables that included dental caries, based on the DMFT: at least one decayed tooth (yes; no); number of teeth present ( $\leq 13$ teeth; $\geq 14$ teeth), using the median as the cut-off point, because standard deviation of number of teeth was high (SD 6.8) and only natural teeth were considered - teeth indicated 
for extraction were not included; and the absence of need for dental prostheses, ("yes", when there was no need, included individuals that had all their teeth and/or showed some type of prosthesis in good conditions, not needing replacement; "no", when the individuals needed some type (or replacement) of fixed/removable prosthesis, or a combination of both, in the upper or lower jaw).

\section{Statistical analysis}

Statistical analyses were performed using Poisson regression with robust variance adjustment, using Stata 9.0 software (Stata, College Station, USA). The analysis took into account the cluster sample and the sampling stages of this study. Representativeness was ensured by adjusting the sample using the svyset-weight function in Stata 9.0, by assigning different eights to each group studied. ${ }^{23}$

Initially, bivariate analysis (crude Poisson regression) was performed between the SOC and the oral health variables (dental attendance within the previous year, reason for dental attendance, dental caries, number of teeth present and need for dental prostheses). Those that showed statistically significant associations with the SOC (number of teeth present and need for dental prostheses) were considered dependent variables of this study, and the others were treated as potential confounders. The level of statistical significance in all analyses was $5 \%(p<0.05)$.

Bivariate analysis was then performed between the independent variables and the outcomes. A significance level of $\leq 0.25$ was established as the cut-off point for the selection of variables that would be included in the multivariate model, to avoid the exclusion of variables that could act as confounders. Bivariate analysis was performed between the sociodemographic variables and the outcomes. These variables were included in the final model, regardless of their significance level.

Three multivariate Poisson regression models were adjusted, one for each outcome, using the backward method. Analyses were performed to define the final model and identify possible confounding variables. At each stage, those that did not have at least one category with $p<0.05$ were removed, starting with the highest $p$-value. Thus, variables with $p>0.05$ that did not cause changes in the risk estimates of other variables were excluded from the final model, with the exception of sociodemographic variables, which were maintained, regardless of the observed result.

This study is part of a research project called "Assessment of Dental Impact on the Daily Performance of Individuals from 50 to 74 years in Porto Alegre/RS," approved by the Research Ethics Committee of the School of Dentistry of the Universidade Federal do Rio Grande do Sul - UFRGS (Protocol no. 46/05).

\section{Results}

\section{Descriptive analysis}

The study had a response rate of $91 \%$, totaling 720 individuals investigated. The average age of the participants was 60.2 years (SD 7.5), and they were predominantly female $(57.8 \%)$. Two-thirds of the sample showed no dental caries. Less than half had dental attendance within the previous year $(45.2 \%)$, and the prevalence of dental attendance for preventive reasons was $31.8 \%$. It was found that $48.5 \%$ of the sample had 14 or more natural teeth, $21 \%$ were edentulous, $28.5 \%$ had no need for dental prostheses, and only $4 \%$ had all their teeth.

The SOC score ranged from 23 to 91, with a mean of $68(\mathrm{SD}=12.2)$ and median of 69 . More than half of the sample $(53.5 \%)$ showed a strong SOC. With respect to the sociodemographic distribution, high SOC scores were more frequent among women (63.4\%) aged 60 years or older $(60.2 \%)$, with over 6 years of schooling (50.4\%) and a family income between 2 and 5 minimum wages $(40.8 \%)$.

\section{Bivariate and multivariate analysis}

Table 1 presents the results of the bivariate analysis investigating the relationship between the SOC and both behavioral and clinical variables that could be used as outcomes (dental attendance within the previous year, reason for dental attendance, dental caries, number of teeth present and need for dental prostheses), considering that the variables selected were those that were significantly associated: number of teeth present (CI 1.01-1.11; $\mathrm{p}=0.031$ ) and lack of need for dental prostheses (IC 1.03-1.66; $\mathrm{p}=0.028$ ). 
Table 1. Crude Poisson regression between the oral health variables and Sense of Coherence $(n=720)$.

\begin{tabular}{|c|c|c|}
\hline \multirow{2}{*}{ Outcome Variables } & \multicolumn{2}{|c|}{ Sense of Coherence } \\
\hline & PR crude (C195\%) & p-value \\
\hline \multicolumn{3}{|c|}{ Dental Attendance within the previous year* } \\
\hline No & 1.00 & - \\
\hline Yes & $0.98(0.78-1.08)$ & 0.326 \\
\hline \multicolumn{3}{|c|}{ Reason for Dental Attendance* } \\
\hline Curative & 1.00 & - \\
\hline Preventive & $0.93(0.75-1.15)$ & 0.509 \\
\hline \multicolumn{3}{|c|}{ Number of Teeth Present } \\
\hline$\leq 13$ teeth & 1.00 & - \\
\hline$\geqq 14$ teeth & $1.05(1.01-1.11)$ & 0.031 \\
\hline \multicolumn{3}{|c|}{ Absence of Need for Dental Prosthesis } \\
\hline No & 1.00 & - \\
\hline Yes & $1.30(1.03-1.66)$ & 0.028 \\
\hline \multicolumn{3}{|l|}{ Dental Caries } \\
\hline Yes & 1.00 & - \\
\hline No & $0.94(0.85-1.04)$ & 0.290 \\
\hline
\end{tabular}

Table 2 shows the results of the bivariate and multivariate analysis related to the absence of need for prostheses. After adjustment, the lack of need for dental prostheses was $34 \%$ higher among participants who had a strong SOC than among those with a weak SOC $(p=0.015)$. The dental attendance within the previous year, the reason for the dental attendance and the dental caries were included in the multivariate analysis, but were removed from the final model because they were not associated with the outcome and did not alter the risk estimates of the other explanatory variables.

The results of the crude and adjusted analyses between the independent variables and the number of teeth present are reported in Table 3. It was observed that individuals who presented a strong SOC had a $5 \%$ higher prevalence of 14 or more existing teeth than those with a weak SOC ( $p=0.033)$, after adjustment for co-factors. This outcome was also associated with sex and age, in that men had $7 \%$ greater prevalence of 14 or more teeth present than women ( $p=0.006)$, and the younger participants had a $5 \%$ greater prevalence than the older participants $(p=0.046)$, but these variables did not influence the relationship between the SOC and the outcome. The dental attendance variables within the previous year, reason for dental attendance, dental caries and the need for dental prostheses were not associated with the number of teeth present and did not alter the risk estimates of the other variables.

\section{Discussion}

It can be observed from the literature that this is one of the few studies investigating the relation between the SOC and clinical indicators, and studying a sample of adults and the elderly. In Brazil, studies using the SOC scale have focused on schoolchildren and teenagers, whereas this is the first population-based study to explore a different age group.

The majority of studies investigating the relationship between the SOC and oral health in adults were conducted in Finland, using a modified version of the SOC, containing 12 items. ${ }^{12,14,15,18,20}$ Therefore, this study provides information from a group with different characteristics, thus allowing comparisons with the SOC of a population presenting other cultural and behavioral values.

The association found between the SOC and clinical outcomes shows that individuals with a higher SOC have less need for dental prostheses and a higher number of teeth present. These are relevant results because they demonstrate the relationship between the SOC and the measured oral health conditions, in terms of clinical indicators.

Various studies have demonstrated the relationship of the SOC with habits, behavior and oral health conditions, as self-reported. . $^{8,10,12,13,14,30}$ However, the investigation of the relationship of the SOC with clinical health conditions is still scant in the literature. Freire et al. ${ }^{5}$ found an association between SOC and cavities in the posterior teeth of adolescents, a result that was not confirmed by multivariate analysis. ${ }^{5}$ When evaluating the relationship between the SOC and clinical oral health outcomes in adults, Bernabé et al. ${ }^{20}$ found that a higher SOC was associated with fewer cavities and fewer missing teeth, after adjusting for social, demographic and behavioral variables. 
The results of this study indicate that a higher SOC can contribute to a better oral health condition of adults and the elderly, observing also that the social and demographic factors had no influence on this result, thus confirming what was found in the study by Bernabé et al. ${ }^{20}$ The lack of influence of socioeconomic status on the relationship between SOC and oral health behaviors in adults has been observed in previous studies. ${ }^{10,11}$ The finding of this association, in relation to the clinical conditions (number of teeth present and need for dental prostheses), suggests that reinforcing the SOC could result in favorable oral health outcomes, even if there were no changes in socioeconomic status.
For example, individuals with a higher SOC may be more motivated and empowered to seek care in public services, or to find alternatives to access dental care in institutions that offer services free of charge or at lower cost, such as unions and associations.

One of the pathways that the Salutogenic theory proposes is that individuals who have a higher SOC choose health-promoting behaviors for themselves with greater frequency. ${ }^{31}$ In this study, oral health behaviors related to the use of oral health services were not important in the relationship between SOC and outcomes, because their presence in the model caused little or no change in the risk measures. It was

Table 2. Results of crude and adjusted Poisson regression with outcome absence of need for dental prosthesis $(n=720)$.

\begin{tabular}{|c|c|c|c|c|c|c|c|}
\hline \multirow[b]{2}{*}{ Variables } & \multicolumn{7}{|c|}{ Absence of the need for dental prosthesis } \\
\hline & $n^{a}$ & \multicolumn{2}{|c|}{$\mathrm{n}(\%)^{\mathrm{b}}$} & $\mathrm{PR}_{\text {crude }}(\mathrm{Cl} 95 \%)$ & $p$-value & $\begin{array}{l}\text { PR Adjusted } \\
\text { (Cl95\%) }\end{array}$ & $\mathrm{p}$-value \\
\hline \multicolumn{8}{|l|}{ Sense of Coherence } \\
\hline weak & 335 & 82 & $(24.5)$ & 1.00 & - & 1.00 & - \\
\hline strong & 385 & 123 & (31.9) & $1.31(1.03-1.66)$ & 0.028 & $1.34(1.06-1.70)$ & 0.015 \\
\hline \multicolumn{8}{|l|}{ Sex } \\
\hline female & 416 & 124 & $(29.9)$ & 1.00 & - & 1.00 & - \\
\hline male & 304 & 78 & $(25.6)$ & $0.86(0.66-1.11)$ & 0.241 & $0.83(0.64-1.07)$ & 0.144 \\
\hline \multicolumn{8}{|l|}{ Age } \\
\hline $60-74$ years & 338 & 94 & $(27.7)$ & 1.00 & - & 1.00 & - \\
\hline $50-59$ years & 382 & 113 & $(29.5)$ & $1.07(0.85-1.35)$ & 0.581 & $1.15(0.91-1.46)$ & 0.243 \\
\hline \multicolumn{8}{|l|}{ Income (family) } \\
\hline$\leq 2$ wages & 191 & 50 & $(26.2)$ & 1.00 & - & 1.00 & - \\
\hline between 2 and 5 wages & 287 & 83 & $(28.9)$ & $0.10(0.82-1.49)$ & 0.515 & $1.16(0.86-1.56)$ & 0.336 \\
\hline 5 wages & 242 & 72 & $(29.7)$ & $1.14(0.83-1.54)$ & 0.414 & $1.24(0.90-1.71)$ & 0.181 \\
\hline \multicolumn{8}{|l|}{ Education Level } \\
\hline$<6$ years & 292 & 87 & $(29.8)$ & 1.00 & - & 1.00 & \\
\hline$>6$ years & 428 & 118 & $(27.6)$ & $0.92(0.73-1.17)$ & 0.515 & $0.84(0.66-1.08)$ & 0.174 \\
\hline \multicolumn{8}{|c|}{ Dental Attendance within the previous year ${ }^{c}$} \\
\hline no & 393 & 120 & (30.5) & 1.00 & - & & \\
\hline yes & 324 & 84 & $(25.9)$ & $0.85(0.67-1.08)$ & 0.176 & & \\
\hline \multicolumn{8}{|c|}{ Reason for Dental Attendance ${ }^{c}$} \\
\hline curative & 489 & 142 & $(29.0)$ & 1.00 & - & & \\
\hline preventive & 228 & 62 & $(27.2)$ & $0.93(0.73-1.21)$ & 0.612 & & \\
\hline \multicolumn{8}{|l|}{ Dental Caries } \\
\hline yes & 240 & 68 & (28.3) & 1.00 & - & & \\
\hline no & 480 & 137 & $(28.5)$ & $1.01(0.78-1.29)$ & 0.953 & & \\
\hline
\end{tabular}

PR: Prevanlence Ratio; Cl: Conficence Interval.

a Sample description.

b Prevalence of outcome.

'Excluding those who never underwent dental attendance $(n=717)$. 
demonstrated that, in this case, the effect of the SOC on the oral conditions cannot be explained only by behavioral factors. However, considering that the model investigated included few behavioral variables, we cannot rule out the possibility that there were other behavioral factors and clinical conditions that were not explored in this study, which could have an influence on the outcomes, explaining the relationships found.

Table 3. Results of the crude and adjusted Poisson regression with outcome number of teeth present $(n=720)$.

\begin{tabular}{|c|c|c|c|c|c|c|c|}
\hline \multirow[b]{2}{*}{ Variables } & \multicolumn{7}{|c|}{ Number of teeth present } \\
\hline & $n^{a}$ & & $\mathrm{n}(\%)^{\mathrm{b}}$ & $\begin{array}{l}\text { PR crude } \\
\text { (Cl95\%) }\end{array}$ & $\mathrm{p}$-value & $\begin{array}{l}\text { PR Adjusted } \\
\text { (C195\%) }\end{array}$ & $\mathrm{p}$-value \\
\hline \multicolumn{8}{|l|}{ Sense of Coherence } \\
\hline weak & 335 & 148 & $(44.2)$ & 1.00 & - & 1.00 & - \\
\hline strong & 385 & 201 & $(52.2)$ & $\begin{array}{c}1.05 \\
(1.00-1.11)\end{array}$ & 0.031 & $\begin{array}{c}1.05 \\
(1.01-1.11)\end{array}$ & 0.033 \\
\hline \multicolumn{8}{|l|}{ Sex } \\
\hline female & 416 & 185 & $(44.6)$ & 1.00 & - & 1.00 & - \\
\hline male & 304 & 171 & (56.3) & $\begin{array}{c}1.08 \\
(1.03-1.14)\end{array}$ & 0.003 & $\begin{array}{c}1.07 \\
(1.02-1.13)\end{array}$ & 0.006 \\
\hline \multicolumn{8}{|l|}{ Age } \\
\hline $60-74$ years & 338 & 152 & $(45.1)$ & 1.00 & - & 1.00 & - \\
\hline $50-59$ years & 382 & 203 & $(52.9)$ & $\begin{array}{c}1.05 \\
(1.01-1.11)\end{array}$ & 0.038 & $\begin{array}{c}1.05 \\
(1.01-1.11)\end{array}$ & 0.046 \\
\hline \multicolumn{8}{|l|}{ Income (family) } \\
\hline$\leq 2$ wages & 191 & 92 & $(48.2)$ & 1.00 & - & 1.00 & - \\
\hline between 2 and 5 wages & 287 & 141 & $(49.1)$ & $\begin{array}{c}1.01 \\
(0.95-1.07)\end{array}$ & 0.837 & $\begin{array}{c}1.01 \\
(0.95-1.08)\end{array}$ & 0.786 \\
\hline 5 wages & 242 & 116 & $(47.9)$ & $\begin{array}{c}1.00 \\
(0.94-1.06)\end{array}$ & 0.961 & $\begin{array}{c}1.00 \\
(0.94-1.07)\end{array}$ & 0.973 \\
\hline \multicolumn{8}{|l|}{ Education Level } \\
\hline$<6$ years & 292 & 138 & $(47.3)$ & 1.00 & - & 1.00 & - \\
\hline$>6$ years & 428 & 211 & $(49.3)$ & $\begin{array}{c}1.01 \\
(0.96-1.07)\end{array}$ & 0.592 & $\begin{array}{c}1.00 \\
(0.95-1.06)\end{array}$ & 0.911 \\
\hline \multicolumn{8}{|c|}{ Dental Attendance within the previous yearc } \\
\hline no & 393 & 194 & $(49.4)$ & 1.00 & - & & \\
\hline yes & 324 & 153 & $(47.2)$ & $\begin{array}{c}0.98 \\
(0.94-1.03)\end{array}$ & 0.568 & & \\
\hline \multicolumn{8}{|c|}{ Reason for Dental Attendancec } \\
\hline curative & 489 & 248 & $(50.7)$ & 1.00 & - & & \\
\hline preventive & 228 & 99 & $(43.4)$ & $\begin{array}{c}0.95 \\
(0.90-1.00)\end{array}$ & 0.070 & & \\
\hline \multicolumn{8}{|l|}{ Dental caries } \\
\hline yes & 240 & 112 & $(46.7)$ & 1.00 & - & & \\
\hline no & 480 & 237 & $(49.4)$ & $\begin{array}{c}1.02 \\
(0.97-1.07)\end{array}$ & 0.494 & & \\
\hline \multicolumn{8}{|l|}{ Need for Dental Prosthesis } \\
\hline yes & 515 & 248 & $(48.2)$ & 1.00 & - & & \\
\hline no & 205 & 101 & $(49.3)$ & $\begin{array}{c}1.01 \\
(0.95-1.06)\end{array}$ & 0.787 & & \\
\hline
\end{tabular}

PR: Prevalence Ratio; $\mathrm{Cl}$ : Confidence Interval.

a Sample description.

b Prevalence of outcome.

cExcluding those who never underwent dental attendance $(n=717)$. 
In cross-sectional study designs, the exposure and outcome are simultaneously assessed; therefore, a temporal relationship between them cannot be established. Dental caries was measured at the time of the study, whereas tooth loss may have occurred a long time earlier. Nevertheless, these type of studies are important indicators of the relationship between the variables.

A noteworthy matter for discussion is the clinical relevance of the findings. In the case of the association between SOC and number of teeth, the difference between the groups was small and did not seem to be clinically important. However, it is believed that the homogeneity of the sample in relation to SOC levels may influence this outcome. The SOC score can range from 13 to 91 . In this population, it ranged from 23 to 91, with a mean score of $68(\mathrm{SD}=12.2)$. Even the participants classified with a weak SOC had high scores, most of which were very close to the median value (md 69), established as the cutoff for defining the categories. This distribution confirmed the relative homogeneity of the sample, which may have hindered the identification of differences of greater magnitude between the groups. This study, like others, ${ }^{9,14,16,32}$ chose to analyze the SOC as a categorical variable and not as a continuous variable, which also may have contributed to this result because categorization leads to loss of information.

\section{References}

1. Eriksson M, Lindström B. Validity of Antonovsky's sense of coherence scale: a systematic review. J Epidemiol Community Health. 2005;59(6):460-6. doi:10.1136/jech.2003.018085

2. Eriksson M, Lindström B. Antonovsky's Sense of Coherence scale and its relation with quality of life: a systematic review. J Epidemiol Community Health. 2007;61(11):938-44. doi:10.1136/jech.2006.056028

3. Antonovsky A. Unraveling the mystery of health - how people manage stress and stay well. London: Jossey-Bass; 1987.

4. Freire M, Hardy R, Sheiham A. Mothers' Sense of Coherence and their adolescent children's oral health status and behaviours. Community Dent Health. 2002;19(1):24-31.

5. Freire MCM, Sheiham A, Hardy R. Adolescents' sense of coherence, oral health status, and oral health-related
The Salutogenic theory has been identified as an important resource that can be used in the field of health promotion in all age groups, offering possibilities of intervention that go beyond the limits of oral health clinical specialties. Therefore, it may be used as a basis for public health policies to promote oral health. The SOC framework may be used to foster individual and collective empowerment, thus enabling people to identify and use available resources to adopt healthy behaviors to improve their health and quality of life.

\section{Conclusion}

The findings of this study showed that individuals with a strong SOC presented more number of teeth present and less need of dental prostheses than those with weak SOC, after adjustment for demographic, behavioral or social factors. However, the importance of subsequent longitudinal studies to clarify the relationship between SOC and oral health is recognized.

\section{Acknowledgements}

The authors wish to acknowledge Fundação de Amparo à Pesquisa do Estado do Rio Grande do Sul - FAPERGS (no. 8-04/2006), the Conselho Nacional de Desenvolvimento Científico e Tecnológico - CNPq, volunteers and research group.

behaviours. Community Dent Oral Epidemiol. 2001;29(3):204-12. doi:10.1034/j.1600-0528.2001.290306.x

6. Savolainen J, Knuuttila M, Suominen-Taipale L, Martelin

T, Nordblad A, Niskanen M, et al. A strong sense of coherence promotes regular dental attendance in adults. Community Dent Health. 2004;21(4):271-6.

7. Silva AN, Mendonça MHM, Vettore MV. A salutogenic approach to oral health promotion. Cad Saude Publica 2008;24(Suppl 4):s521-30. doi:10.1590/S0102-311X2008001600005

8. Ayo-Yusuf OA, Reddy PS, van den Borne BW. Adolescents' sense of coherence and smoking as longitudinal predictors of self-reported gingivitis. J Clin Periodontol. 2008;35(11):931-7. doi:10.1111/j.1600-051X.2008.01319.x

9. Bonanato K, Paiva SM, Pordeus IA, Ramos-Jorge ML, Barbabela D, Allison PJ. Relationship between mothers' sense of coherence and oral health status of preschool children. Caries Res. 2009;43(2):103-9. doi:10.1159/000209342 
10. Bernabé E, Kivimäki M, Tsakos G, Suominen-Taipale AL, Nordblad A, Savolainen J, et al. The relationship among sense of coherence, socio-economic status, and oral health-related behaviours among Finnish dentate adults. Eur J Oral Sci. 2009;117(4):413-8. doi:10.1111/j.1600-0722.2009.00655.x

11. Bernabé E, Tsakos G, Watt RG, Suominen-Taipale $\mathrm{AL}$, Uutela A, Vahtera J, et al. Structure of the sense of coherence scale in a nationally representative sample: the Finnish Health 2000 survey. Qual Life Res. 2009;18(5):629-36. doi:10.1007/s11136-009-9469-z

12. Bernabé E, Watt RG, Sheiham A, Suominen-Taipale AL, Nordblad A, Savolainen J, et al. The influence of sense of coherence on the relationship between childhood socioeconomic status and adult oral health-related behaviours. Community Dent Oral Epidemiol. 2009;37(4):357-65. doi:10.1111/j.1600-0528.2009.00483.x

13. Savolainen JJ, Suominen-Taipale AL, Uutela AK, Martelin TP, Niskanen MC, Knuuttila ML. Sense of coherence as a determinant of toothbrushing frequency and level of oral hygiene. J Periodontol. 2005;76(6):1006-12. doi:10.1902/jop.2005.76.6.1006

14. Savolainen J, Suominen-Taipale AL, Hausen H, Harju P, Uutela A, Martelin T, et al. Sense of coherence as a determinant of the oral health-related quality of life: a national study in Finnish adults. Eur J Oral Sci. 2005;113(2):121-7. doi:10.1111/j.1600-0722.2005.00201.x

15. Savolainen J, Suominen-Taipale A, Uutela A, Aromaa A, Härkänen T, Knuuttila M. Sense of Coherence associates with oral and general health behaviours. Community Dent Health. 2009;26(4):197-203.

16. Emami E, Allison PJ, de Grandmont $\mathrm{P}$, Rompré $\mathrm{PH}$, Feine JS. Better oral health related quality of life: type of prosthesis or psychological robustness? J Dent. 2010;38(3):232-6. doi:10.1016/j.jdent.2009.11.002

17. Sanders AE, Slade GD, Turrell G, Spencer AJ, Marcenes W. Does psychological stress mediate social deprivation in tooth loss? J Dent Res. 2007;86(12):1166-70. doi:10.1177/154405910708601205

18. Eriksson M, Lindström B. Antonovsky's sense of coherence scale and the relation with health: a systematic review. J Epidemiol Community Health. 2006;60(5):376-81. doi:10.1136/jech.2005.041616

19. Lindström B, Eriksson M. Salutogenesis. J Epidemiol Community Health. 2005;59(6):440-2. doi:10.1136/jech.2005.034777

20. Bernabé E, Watt RG, Sheiham A, Suominen-Taipale AL, Uutela A, Vehkalahti MM, et al. Sense of Coherence and oral health in dentate adults: findings from the finnish health 2000 survey. J Clin Periodontol. 2010;37(11):981-7. doi:10.1111/j.1600-051X.2010.01604.x

21. Instituto Brasileiro de Geografia e Estatística. Censo Demográfico 2000: Resultados. Rio de Janeiro: IBGE; 2000.

22. Instituto Brasileiro de Geografia e Estatística. Perfil dos idosos responsáveis pelos domicílios no Brasil 2000 [Internet]. Rio de Janeiro: IBGE; 2002 [cited 2015 Aug 02] . Available from: http://www.ibge.gov.br/home/estatistica/ populacao/perfilidoso/perfidosos2000. pdf

23. Fontanive VN, Abegg C, Tsakos G, Oliveira M. The association between clinical oral health and general quality of life: a population-based study of individuals aged 50-74 in Southern Brazil. Community Dent Oral Epidemiol. 2013;41(2):154-62. doi:10.1111/j.1600-0528.2012.00742.x

24. Brasil. Ministério da Saúde. Área Técnica de Saúde Bucal. Projeto SB2000: condições de saúde bucal da população brasileira no ano 2000: manual do examinador. Brasília: 2001.

25. Biomedcentral. The 13-item Sense of Coherence Questionnaire [Internet]. [place unknown: publisher unknown]: [updated unknown; cited 2015 Jul 15]. Available from: http://www.biomedcentral.com/content/ supplementary/1751-0759-2-4-S1.doc

26. Bonanato K, Branco DBT, Mota JPT, Ramos-Jorge ML, Paiva SM, Pordeus IA, et al. Trans-cultural adaptation and psychometric properties of the 'Sense of Coherence Scale' in mothers of preschool children. Interam J Psychol. 2009;43(1):144-53.

27. Suominen S, Helenius H, Blomberg H, Uutela A, Koskenvuo M. Sense of Coherence as a predictor of subjective state of health: results of 4 years of follow-up of adults. J Psychosom Res. 2001;50(2):77-86. doi:10.1016/S0022-3999(00)00216-6

28. Streiner D, Norman GR. Health Measurement Scales: a practical to their development and use. Oxford: Oxfors University Press, 2003.

29. Naaldenberg J, Tobi H, van den Esker F, Vaandrager L. Psychometric properties of the OLQ-13 scale to measure Sense of Coherence in a community-dwelling older population. Health Qual Life Outcomes. 2011;9:37. doi:10.1186/1477-7525-9-37

30. Ayo-Yusuf OA, Reddy PS, van den Borne BW. Longitudinal association of adolescents' Sense of Coherence with tooth-brushing using an integrated behaviour change model. Community Dent Oral Epidemiol. 2009;37(1):68-77. doi:10.1111/j.1600-0528.2008.00444.x

31. McCubbin HI, Thompson EA, Thompson AI, Fromer JE. The Sense of Coherence: an historical and future perspective. Isr J Med Sci. 1996;32(3-4):170-8.

32. Kouvonen AM, Väänänen A, Woods SA, Heponiemi T, Koskinen A, Toppinen-Tanner S. Sense of Coherence and diabetes: a prospective occupational cohort study. BMC Public Health. 2008;8(1):46-57. doi:10.1186/1471-2458-8-46 